\title{
Outburst cavity formation in the working face driven along the outburst-prone coal seam
}

\author{
Oleksandr Krukovskyi ${ }^{1, *}$, Viktoriia Krukovska ${ }^{1}$, and Wen Zhang $^{2}$ \\ ${ }^{1}$ Institute of Geotechnical Mechanics named by N. Poljakov of National Academy of Sciences of \\ Ukraine, 49005, Dnipro, Simferopolska Str., 2a, Ukraine \\ ${ }^{2}$ College of Construction Engineering, Jilin University, 130021, Changchun, Ximinzhu Str., 938, China
}

\begin{abstract}
In Donbas coal mines, coal and gas outbursts present a major risk for the mining operation safety. Rapidly released energy can cause serious damage to the mine's personnel and production equipment. Modern numerical methods allow modeling complex physical processes occurred during the coal and gas outbursts. The mathematical model was developed for the coupled processes of the rock massif deformation and gas filtration in the mine face near the tectonic dislocation. When solving the problem, the finite element method was used. The calculation results of the stresses, inelastic deformation zones, pressures of methane and configuration of cavity of the coal and gas outburst are represented in the paper. It is shown that an outburst cavity is formed inside the coal seam and is bounded from above and from below by the host rocks. The calculated geometry of the fracture cavity at the gas-dynamic phenomena in the mine working face coincides with actual data obtained in the mines of Donbas and, therefore, confirms the adequacy of the developed mathematical model.
\end{abstract}

\section{Introduction}

Coal and gas outbursts are threatening the safety of mining operations in the coal mines of the central region of Donbas and are one of the main obstacles to the intensification of underground mining and the introduction of new non-traditional and safe technologies for mining coal seams $[1,2]$. In the process of outburst, a large amount of gas and fractured coal mass is thrown into the mine working. Rapidly released energy can cause serious damage to mine personnel and production equipment. The complexity of the mechanism for the occurrence of such gas-dynamic phenomena hampers the development of effective antioutburst measures. Modern numerical methods allow to solve complex systems of coupled equations that describe the physical processes occurring during the outburst of coal and gas: the deformation of the coal and rocks, filtration and desorption of gas [3]. They allow you to take into account the properties of the rocks and the geometry of the workings. There were developed many numerical models of gas-dynamic processes [4-9], many valuable results were obtained. However, the forming of outburst cavity in the coal seam was not ever modeled. Therefore, the aim of this work is to study the features of the formation of a fracture cavity in the process of outburst of coal and gas in the mine working near the

\footnotetext{
${ }^{*}$ Corresponding author: igtm@ukr.net
} 
tectonic faults and to compare the results of numerical simulation with actual data.

\section{Methods}

The coupled processes of the rock massif deformation and gas filtration in a disturbed area are described by a system of equations [10-13]:

$$
\begin{gathered}
c_{g} \frac{\partial u_{i}}{\partial t}=\sigma_{i j, j}+X_{i}(t)+P_{i}(t) \\
\frac{\partial p}{\partial t}=\frac{K}{2 m \mu}\left(\frac{\partial^{2} p^{2}}{\partial x^{2}}+\frac{\partial^{2} p^{2}}{\partial y^{2}}\right)+q(t),
\end{gathered}
$$

where $c_{g}$ - the damping coefficient, $\mathrm{kg} /\left(\mathrm{m}^{3} \cdot \mathrm{s}\right) ; u_{i}$ - the displacements, $\mathrm{m} ; t$ - time, $\mathrm{s} ; \sigma_{i j, j}-$ the derivatives of the stress tensor components along horizontal axis $x$ and vertical axis $y$, $\mathrm{Pa} / \mathrm{m} ; X_{i}(t)$ - the projections of the external forces acting on the volume unit of a solid body, $\mathrm{N} / \mathrm{m}^{3} ; P_{i}(t)$ - the projections of forces due to gas pressure in the porous fractured space, $\mathrm{N} / \mathrm{m}^{3} ; p$ - the gas pressure, $\mathrm{Pa} ; x, y$ - coordinates, $\mathrm{m} ; K$ - the absolute permeability coefficients, $\mathrm{m}^{2} ; m$ - porosity; $\mu$ - gas viscosity, $\mathrm{Pa} \cdot \mathrm{s} ; q(t)$ - the gas release function, $\mathrm{Pa} / \mathrm{s}$.

In most cases, gas-dynamic phenomena occur near tectonic faults, where the coal will be ground and has an initial permeability on $10-20 \mathrm{~m}$ from both sides of the fault. Technological permeability $k$, which depends on the components of the stress tensor [14], is superimposed on the field of initial, tectonic permeability $k_{\text {tect }}$ :

$$
\begin{gathered}
K=k+k_{\text {tect }} ; \\
k= \begin{cases}0 & \text { for } Q^{*}<0.7 ; P^{*}>0.25 ; \\
k_{\min } & \text { for } 0.7<Q^{*}<0.8 ; \\
e^{0.26 Q^{*}-4.65} & \text { for } Q^{*}>0.8 ; P^{*}>0.1 \\
k_{\max } & \text { for } Q^{*}>0.8 ; P^{*}<0.1,\end{cases}
\end{gathered}
$$

where $Q^{*}=\left(\sigma_{1}-\sigma_{3}\right) / \gamma H$ - the parameter characterizing the diversity of the stress field components; $P^{*}=\sigma_{3} / \gamma H$ - the parameter characterizing the unloading of rocks from the rock pressure; $\sigma_{1}, \sigma_{3}$ - maximum and minimum components of the principal stress tensor, $\mathrm{Pa}$; $\gamma$ - the averaged weight of the overlying mine rocks, $\mathrm{N} / \mathrm{m}^{3} ; H$ - the mining depth, $\mathrm{m} ; k_{\min }-$ minimum permeability coefficient sufficient to start the filtration, $\mathrm{m}^{2} ; k_{\max }$ - fracture permeability, $\mathrm{m}^{2}$.

The initial and boundary conditions for the task set:

$$
\begin{aligned}
& \left.\sigma_{y y}\right|_{t=0}=\gamma H ;\left.\quad \sigma_{x x}\right|_{t=0}=\lambda \gamma H ; \\
& \left.u_{x}\right|_{t=0}=0 ;\left.\quad u_{y}\right|_{t=0}=0 ; \\
& \left.p\right|_{t=0}=p_{0} ; \\
& \left.u_{x}\right|_{\Omega_{1}}=0 ;\left.\quad u_{y}\right|_{\Omega_{2}}=0 ; \\
& \left.p\right|_{\Omega_{1}}=p_{0} ;\left.\quad p\right|_{\Omega_{2}}=p_{0} ; \\
& \left.p\right|_{\Omega_{3}(t)}=p_{0} ;\left.p\right|_{\Omega_{4}}=0.1 \mathrm{MPa}
\end{aligned}
$$


where $\sigma_{x x}, \sigma_{y y}$ - components of the stress tensor, $\mathrm{Pa} ; \lambda$ - the side thrust coefficient; $u_{x}, u_{y}-$ components of the displacement vector, $\mathrm{m} ; p_{0}$ - the methane pressure in the virgin massif, $\mathrm{Pa} ; \Omega_{1}$ - the vertical boundaries of the outer contour; $\Omega_{2}$ - the horizontal boundaries of the outer contour; $\Omega_{3}(t)$ - the time-varying boundary of the filtering area; $\Omega_{4}$ - the internal contour (mine working).

Let the mine working face of $3 \mathrm{~m}$ height be at a distance of $7.75 \mathrm{~m}$ from the tectonic fault with a displacement amplitude of $1 \mathrm{~m}$, surrounded by a ten-meter zone of broken coal $\left(l_{d}=10 \mathrm{~m}\right)$. The coal seam thickness is $1.5 \mathrm{~m}$, the depth of the excavation is $1000 \mathrm{~m}$. The gas content of coal is $20 \mathrm{~m}^{3} / \mathrm{t}, p_{0}=8 \mathrm{MPa}$.

The properties of coal in the disrupted zone near the tectonic fault, (Fig. 1): the cohesion $C$ decreases linearly, and the permeability $k_{\text {tect }}$ increases linearly from the boundary of the disrupted zone to the tectonic fault, the tensile strength $\sigma_{\mathrm{t}}$ is approximately zero:

$$
\begin{aligned}
& C=C_{0}-\frac{\left(C_{0}-C_{\min }\right)\left(x_{d}+l_{d}-x\right)}{l_{d}} ; \\
& k_{\text {tect }}=\frac{k_{\max }\left(x_{d}+l_{d}-x\right)}{l_{d}} ; \\
& \sigma_{t} \approx 0 ; \text { for } x \in\left[x_{d} ; x_{d}+l_{d}\right],
\end{aligned}
$$

where $C_{0}$ - the coal cohesion in the unbroken zone, MPa; $C_{0}$ - the minimum cohesion value in the broken zone, MPa; $x_{d}-x$ coordinate of the tectonic fault, $\mathrm{m} ; l_{d}-$ the length of the broken zone, $\mathrm{M} ; \sigma_{t}-$ прочность на растяжение, MPa.

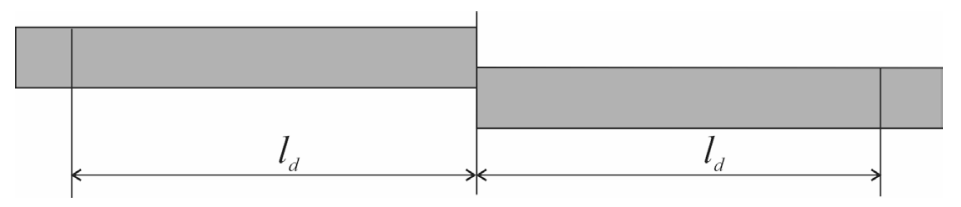

Fig. 1. Coal seam section with tectonic fault.

The condition for the formation of the outburst cavity is the belonging of a finite element to the area of inelastic deformations caused by tensile stresses, and the fulfillment of the criterion for the filtration of methane gradient to exceed the critical value $\operatorname{grad} p>P_{c}$, accepted here $P_{c}=2 \cdot 10^{7} \mathrm{~Pa} / \mathrm{m}$.

For the mathematical description of the process of rocks changeover into a disturbed state, the Mohr-Coulomb failure theory is applied. The problem is solved by the finite element method embodied in authors' computer program.

\section{Results and discussion}

In the vicinity of a tectonic fault, in the zone of a disrupted coal seam, the area of increased diversity of the stress field components $\left(Q^{*}>0.4\right)$ rapidly increases into in the coal seam. The zone of inelastic deformations (this zone is shown in red) is rapidly growing from the mine face (Fig. 2). The pressure of methane in the coal seam near the mine quickly falls, so the relative pressure isobars are tight to the exposed surface. The pressure gradients and the filtration rate of methane take very high values, the permeability of coal is growing rapidly - coal is carried out and a cavity is formed in the coal seam, the length of which reaches $6.75 \mathrm{~m}$ under given initial and boundary conditions. Then the growth of the cavity stops (Fig. 2d), the flow rates of methane fall, the pressure of methane in the coal seam continues to slowly decrease - the geomechanical processes and the process of methane filtration return to the quasisteady regime. The time course of the dynamic process is $10 \mathrm{~s}$. 
As can be seen from Figure 2, the fracture cavity is located within the coal seam, from above and below it is limited to enclosing rocks. The vertical section of the fracture cavity has a rectangular shape, with a curved end.

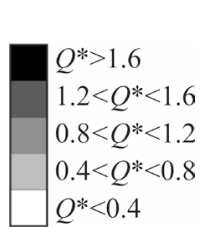

a)

b)

c)
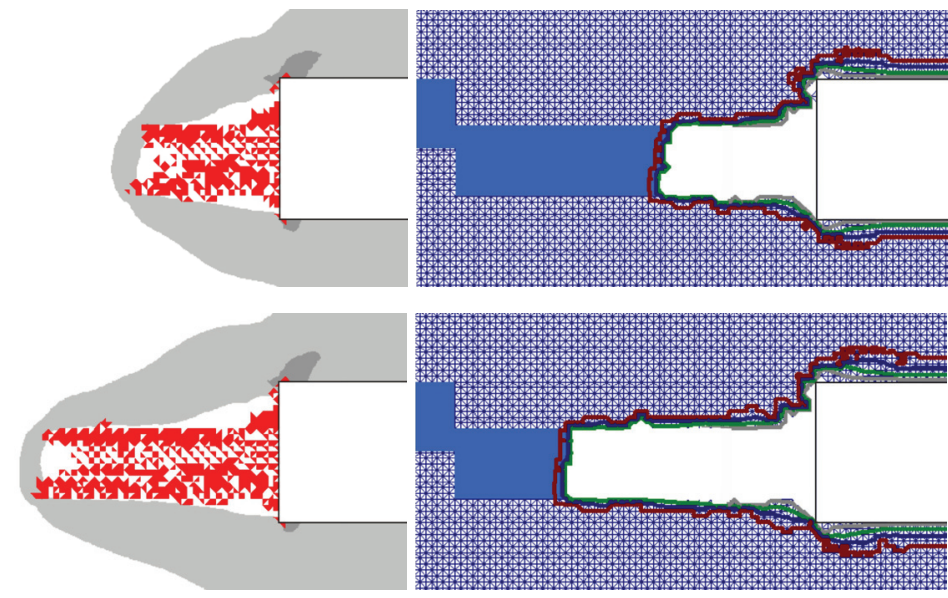

d)

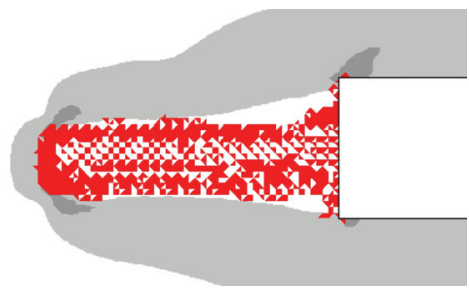

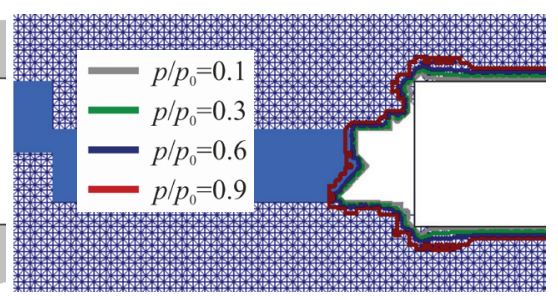
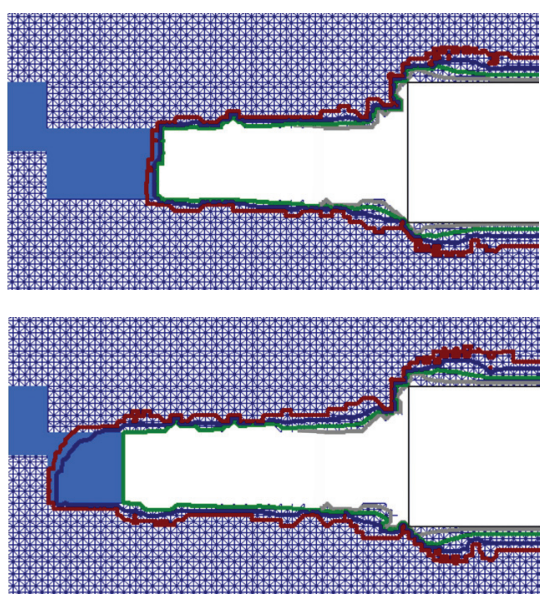

Fig. 2. The distribution of parameter $Q^{*}$ values and inelastic deformation zones (left side), fracture cavity, methane relative pressure $p / p_{0}$ (right side) in the outburst-prone zone near the tectonic fault, vertical section: a) $t=2 \mathrm{~s}$; b) $t=4 \mathrm{~s}$; c) $t=6 \mathrm{~s}$; d) $t=10 \mathrm{~s}$.

In the horizontal section, the shape of the fracture cavity also almost repeats the contour of the inelastic deformation zone, (Fig. 3). It has the shape of an irregular ellipse, the major axis of which is perpendicular to the axis of mine working.

Let us compare the calculated results obtained by the shape of the fracture cavity with the actual data.

In 1976, at the "Hlyboka" mine of the Production Association "Donetskvuhillia" in the gutter, horizon $719 \mathrm{~m}$, coal seam $\mathrm{h}_{8}$, during the removal of the rock mass there was a sudden outburst, (Fig. 4). Outburst intensity was 60 tons of coal and $3000 \mathrm{~m}^{3}$ of methane. The depth of the cavity of destruction was $6 \mathrm{~m}$, width was $15 \mathrm{~m} \mathrm{[15].}$

In 1979, at the V.R. Menzhynskyi mine Production Association "Pervomaiskvuhillia", in the southern gutter, the horizon $845 \mathrm{~m}$, coal seam $L_{4}$, during coal extraction with a jackhammer, a sudden outburst occurred near the tectonic fault, (Fig. 5). Outburst intensity was 70 tons of coal and $5000 \mathrm{~m}^{3}$ of methane [15]. 


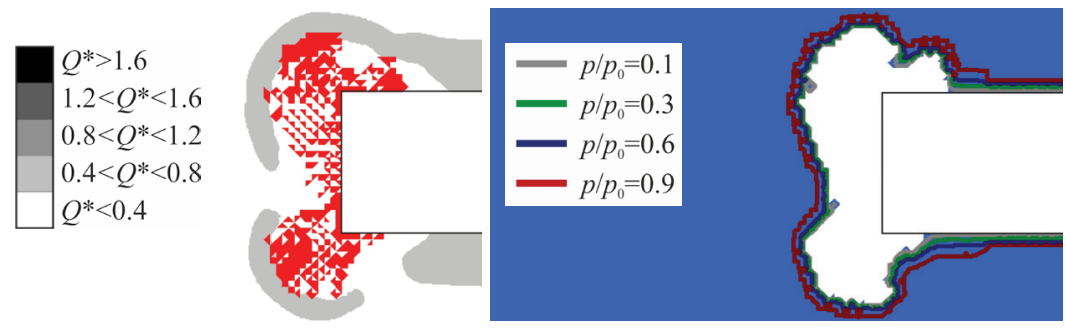

a)
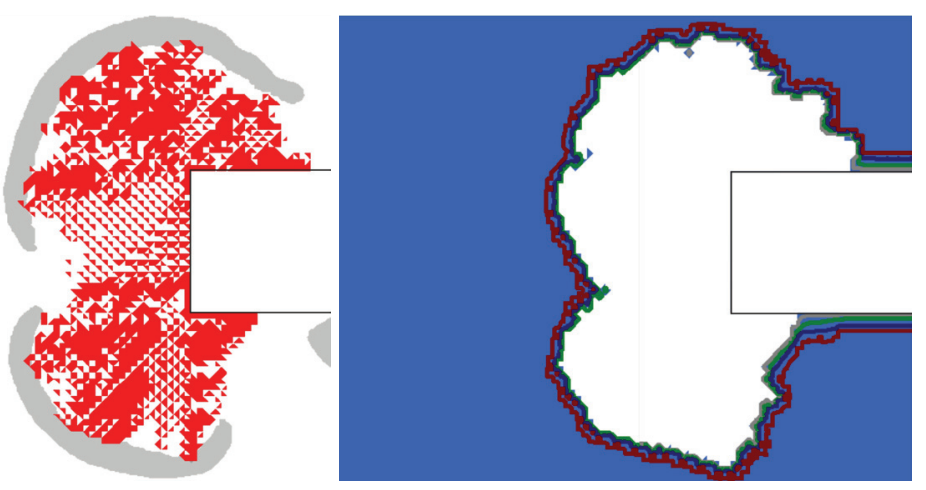

b)

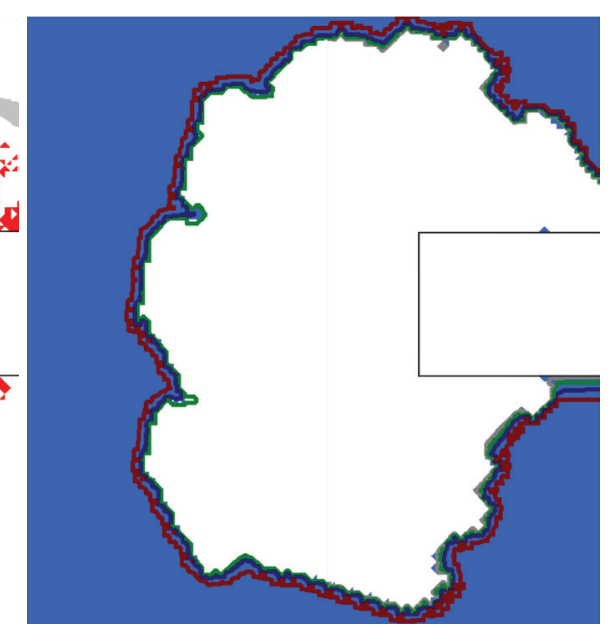

c)

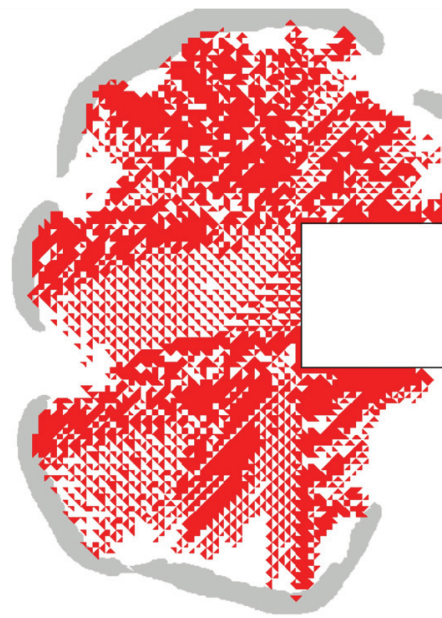

Fig. 3. The distribution of parameter $Q^{*}$ values and inelastic deformation zones (left side), the cavity of destruction, the relative pressure of methane $p / p_{0}$ (right side) in the outburst-prone zone near the tectonic fault, horizontal section: a) $t=2 \mathrm{~s}$; b) $t=4 \mathrm{~s}$; c) $t=10 \mathrm{~s}$.

Thus, both calculated and actual data suggest that in the considered case the outburst cavity is located within the coal seam, from above and below it is limited to enclosing rocks. The vertical section of the fracture cavity has a rectangular shape, possibly with a curved end, the horizontal section is the shape of an irregular ellipse, the major axis of which is perpendicular to the axis of mine working. Comparing Figures 2, 3 and 4, 5, it can be seen that, in general, the calculated shape of the fracture cavity for gas-dynamic phenomena in the canopy of the coal seam in the mine working face coincides with the actual data.

When analyzing the available statistical data on outbursts that occurred in the mines of Donbass [15], we find:

- in the vertical section the outburst cavity is located within the coal seam in $75 \%$ of 
cases, captures host rocks - in $25 \%$;

- in the horizontal section, the fracture cavity has the shape of an irregular oval of $58 \%$, is determined by the position relative to the tectonic fault and is limited to the fault plane in $32 \%$ of cases.

a)
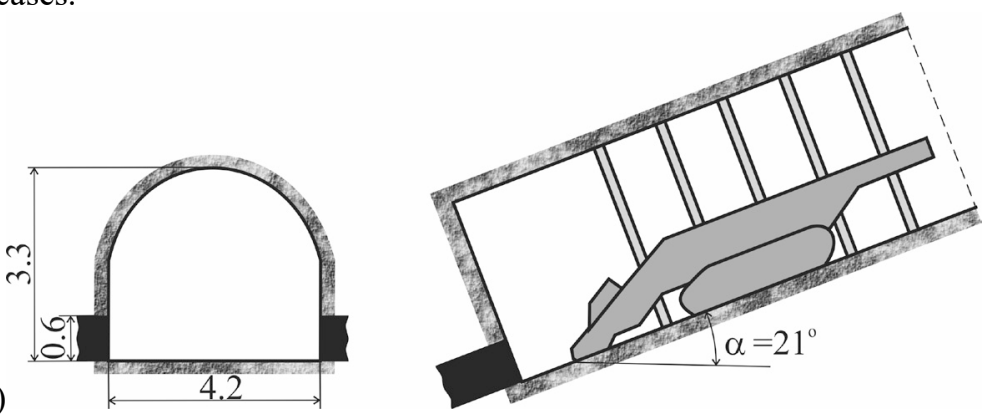

b)
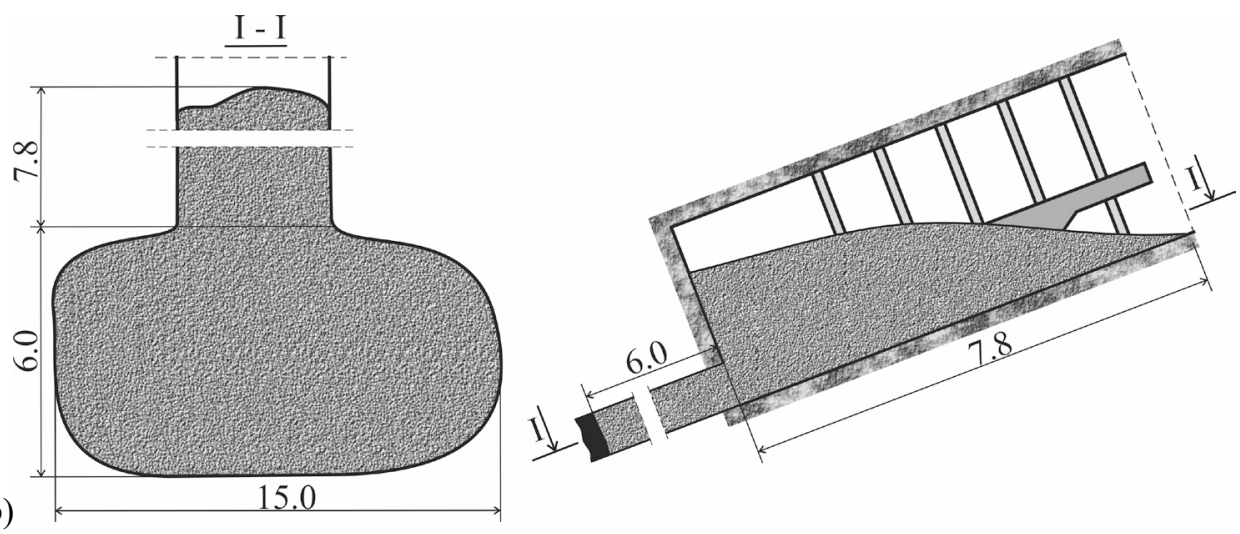

Fig. 4. The scheme of roadway driving and the size of the outburst cavity in the gutter, the mine "Hlyboka" [15]: a - before outburst; b - after outburst.

a)
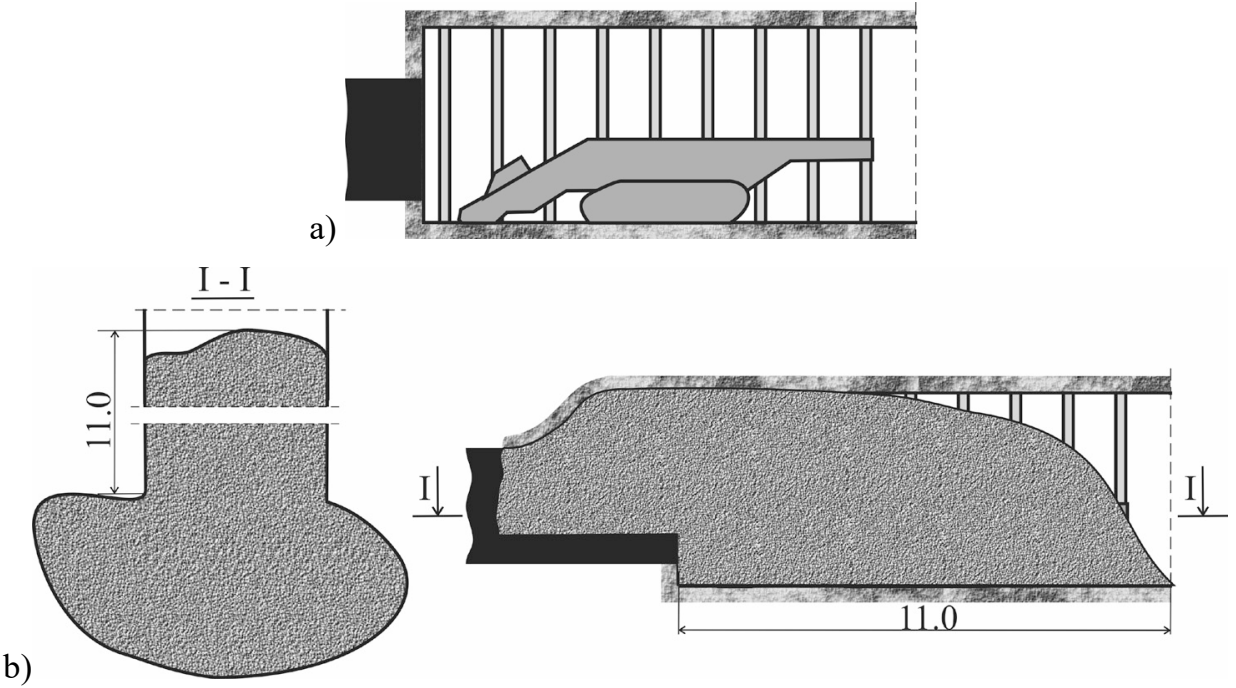

Fig. 5. The scheme of roadway driving the size of the outburst cavity in the southern gutter, V.R. Menzhynskyi mine [15]: a - before the outburst; $b$ - after outburst. 


\section{Conclusions}

A mathematical model has been developed for the coupled processes of elastoplastic deforming the coal-bearing massif and methane filtration in the mine working face at roadheading in the outburst-prone coal seam near the tectonic fault.

As a result of a series of computational experiments, it was shown that the outburst cavity is located within the coal seam; from above and below it is limited to enclosing rocks. The vertical section of the fracture cavity has a rectangular shape with a curved end, the horizontal - the shape of an irregular ellipse, the major axis of which is perpendicular to the axis of mine working. The calculated shape of the fracture cavity in gas-dynamic phenomena in the mine working face coincides with the actual data for the mines of Donbass, which confirms the adequacy of the developed mathematical model.

\section{References}

1. O. Krukovskyi, Y. Bulich, Y.Zemlianaia. Modification of the roof bolt support technology in the conditions of increasing coal mining intensity. E3S Web of Conferences, International Conference Essays of Mining Science and Practice, 109 (2019). https://doi.org/10.1051/e3sconf/201910900042

2. S. Ilin, L. Adorska, V. Samusia, D. Kolosov, I. Ilina. Conceptual bases of intensification of mining operations in mines of Ukraine based on monitoring and condition management of mine hoisting systems. E3S Web of Conferences, International Conference Essays of Mining Science and Practice, 109 (2019). https://doi.org/10.1051/e3sconf/201910900030

3. A. Prusova, O. Minieiev, S. Ryzhova. Simulation of the desorption process of methane adsorbed in a coal rock, taking into account intermolecular sorption interactions in the system "methane-coal". E3S Web of Conferences, International Conference Essays of Mining Science and Practice, 109 (2019). https://doi.org/10.1051/e3sconf/ 201910900073

4. L. Paterson. A model for outbursts in coal. International Journal of Rock Mechanics Mining Science \& Geomechanics, 23, 4 (1986)

5. S. Xue, L. Yuan, J. Wang, et al. A coupled DEM and LBM model for simulation of outbursts of coal and gas. International Journal of Coal Science and Technology, 2, 1 (2015)

6. A. Zhou, K. Wang, L. Wang, et al. Numerical simulation for propagation characteristics of shock wave and gas flow induced by outburst intensity. International Journal of Mining Science and Technology, 25 (2015)

7. H. Li, Z. Feng, D. Zhao, D. Duan. Simulation Experiment and Acoustic Emission Study on Coal and Gas Outburst. Rock Mech Rock Eng, 50 (2017)

8. Q. Tua, Y. Chenga, Q. Liua, et al. Investigation of the formation mechanism of coal spallation through the cross-coupling relations of multiple physical processes. International Journal of Rock Mechanics and Mining Sciences, 105 (2018)

9. H. Qin, J. Wei, S. Li. Analysis of the coal seam spalling-failure mechanism based on the seepage instability theory. PLoS ONE, 14(7) (2019)

10. Krukovskyi, O.P. (2011) Modelling changes of stress-strain state of solid edge during the distance of working face of mine workings. Problemy obchysliuvalnoi mekhaniky $i$ mitsnosti konstruktsii, 17, 175-181

11. Basniev, K.S., Kochina, I.N., Maksimov, V.M. (1993). Podzemnaya gidromehanika. Moskva: Nedra

12. O. Krukovskyi, V. Krukovska. Numerical simulation of the stress state of the layered gas-bearing rocks in the bottom of mine working. E3S Web of Conferences, 
International Conference Essays of Mining Science and Practice, 109 (2019). https://doi.org/10.1051/e3sconf/201910900043

13. S. Skipochka. Conceptual basis of mining intensification by the geomechanical factor. E3S Web of Conferences, International Conference Essays of Mining Science and Practice, 109 (2019). https://doi.org/10.1051/e3sconf/201910900089

14. Krukovska, V.V. (2015). Simulation of coupled processes that occur in coal-rock massif during mining operations. Geotehnicheskaya mehanika [Geo-Technical Mechanics], $121,48-99$

15. Katalog vnezapnyih vyibrosov uglya i gaza na shahtah (Leningrad: Research Institute of Mining Geomechanics and Mine Surveying, Ukrainian Branch, 1989) 